\title{
Potential Threat of a New Pathotype of Papaya leaf distortion mosaic virus Infecting Transgenic Papaya Resistant to Papaya ringspot virus
}

\author{
H.-J. Bau, Y.-J. Kung, J. A. J. Raja, S.-J. Chan, K.-C. Chen, Y.-K. Chen, H.-W. Wu, and S.-D. Yeh
}

First author: Department of Biotechnology, Transworld Institute of Technology, Yunlin, Taiwan, R.O.C.; and second, third, fourth, fifth, sixth, seventh, and eighth authors: Department of Plant Pathology, National Chung Hsing University, Taichung, Taiwan, R.O.C. Accepted for publication 20 March 2008.

\begin{abstract}
Bau, H.-J., Kung, Y.-J., Raja, J. A. J., Chan, S.-J., Chen, K.-C., Chen, Y.-K., Wu, H.-W., and Yeh, S.-D. 2008. Potential threat of a new pathotype of Papaya leaf distortion mosaic virus infecting transgenic papaya resistant to Papaya ringspot virus. Phytopathology 98:848-856.

A virus identified as a new pathotype of Papaya leaf distortion mosaic virus (PLDMV, P-TW-WF) was isolated from diseased papaya in an isolated test-field in central Taiwan, where transgenic papaya lines resistant to Papaya ringspot virus (PRSV) were evaluated. The infected plants displayed severe mosaic, distortion and shoe-stringing on leaves; stunting in apex; and water-soaking on petioles and stems. This virus, which did not react in enzyme-linked immunosorbent assay with the antiserum to the PRSV coat protein, infected only papaya, but not the other 18 plant species tested. Virions studied under electron microscope exhibited mor-

phology and dimensions of potyvirus particles. Reverse transcriptionpolymerase chain reaction conducted using potyvirus-specific primers generated a 1,927-nucleotide product corresponding to the $3^{\prime}$ region of a potyvirus, showing high sequence identity to the $\mathrm{CP}$ gene and $3^{\prime}$ noncoding region of PLDMV. Search for similar isolates with the antiserum against CP of P-TW-WF revealed scattered occurrence of PLDMV in Taiwan. Phylogenetic analysis of PLDMV isolates of Taiwan and Japan indicated that the Taiwan isolates belong to a separate genetic cluster. Since all the Taiwan isolates infected only papaya, unlike the cucurbitinfecting Japanese $P$ type isolates, the Taiwan isolates are considered a new pathotype of PLDMV. Susceptibility of all our PRSV-resistant transgenic papaya lines to PLDMV indicates that the virus is an emerging threat for the application of PRSV-resistant transgenic papaya in Taiwan and elsewhere.
\end{abstract}

Papaya (Carica papaya L.) is established as a cash crop throughout the tropical and subtropical regions due to its easy adaptation to diverse agricultural conditions, high yields and prompt returns. However, the papaya production is seriously limited by the menace of Papaya ringspot virus (PRSV) throughout the world (30). PRSV, which was reported in 1975 from the southern part of Taiwan, destroyed most of the papaya plantations in the country within a few years, causing unprecedented yield loss (37). Pesticidal control of aphids, the insect vectors of PRSV, is ineffective, apart from causing environmental problems. Other failed PRSV control measures include the tactic of avoiding aphid spurts by varying plantation periods and intercropping papaya among barrier crops. The strategy of sensitizing the host system against severe strains of PRSV by pre-infecting the plants with mild PRSV mutants does not work consistently, because of strainspecific protection, though a high cross protection efficacy was achieved initially for a few years $(38,40,42)$. Finally, the uneconomic and highly non-ecofriendly measure of physically preventing the plants from aphids by covering the whole orchard by UV-resistant nylon net has emerged as the sole solution.

Nonexistence of natural resistance in papaya to PRSV $(9,26)$ severely limits the possibility of breeding papaya for effective PRSV resistance. The application of the PRSV tolerant papaya cultivars generated by breeding from a PRSV tolerant genotype $(8,9,10)$ is greatly limited by inferior fruit qualities (16). In the

Corresponding author: S.-D. Yeh; E-mail address: sdyeh@ @ nchu.edu.tw

* The $e$-Xtra logo stands for "electronic extra" and indicates that Figures 1 and 2 appear in color online.

doi:10.1094/PHYTO-98-7-0848

(C) 2008 The American Phytopathological Society past decade, we developed transgenic papaya lines by transforming the papaya cv. Tainung No. 2 with the coat protein $(\mathrm{CP})$ gene of PRSV YK, a severe PRSV strain from Taiwan (35), by Agrobacterium-mediated transformation (4,5). Unlike the PRSV HA 5-1 CP transgenic papaya lines (13), which are resistant mainly against PRSV isolates from Hawaii (15), our PRSV YK $\mathrm{CP}$ transgenic papaya lines are resistant not only to the homologous strain, but also to strains of other geographical origins such as Thailand, Hawaii, and Mexico (4). In the subsequent field trials in a secluded area, the papaya lines proved resistant to PRSV consistently for several years (3).

Identified as early as 1954 in the northern area of Okinawa, Japan, and spread throughout the island during the 1960s (17), Papaya leaf distortion mosaic virus (PLDMV) has been a major constraint to papaya cultivation in Okinawa Islands, Japan (25). Based on several convincing characteristics, such as symptoms on infected papaya plants, host range, nonpersistent transmission by aphids, and viral physical properties, the papaya disease in Okinawa was initially thought to be caused by PRSV (44). However, further electron microscopic and serological studies revealed that the virus was a new species of potyvirus, named Papaya leaf distortion mosaic virus (17). Like W type PRSV, a cucurbitinfecting biotype of PLDMV, designated C type, was also collected from Ishigaki Island, Japan (23). By their inability to infect papaya, $\mathrm{C}$ type PLDMV and $\mathrm{W}$ type PRSV isolates differ from their respective $\mathrm{P}$ type counterparts, which can also infect papaya, in addition to their cucurbit infectivity. A later survey unearthed the presence of PLDMV in Saipan, and Taiwan, as well (18), hinting at its possible prevalence in the Asia-Pacific region. No further studies of PLDMV have been conducted in Taiwan, understandably because of its unrecognized presence in papaya in the overwhelmingly predominant PRSV background. 
A virus isolate, designated P-TW-WF, overcoming the transgenic resistance was obtained during the fourth field trial of the evaluation of our PRSV-resistant papaya transgenic lines, in an isolated-test field in central Taiwan. This virus isolate was found to be serologically unrelated to PRSV and to be a PLDMV P type isolate. However, the failure of the isolate P-TW-WF to infect all the nonpapaya hosts tested, including certain highly PLDMV-susceptible cucurbits, characterized the isolate as a distinct pathotype of $\mathrm{P}$ type PLDMV. An island-wide survey with the antiserum to bacteria-expressed P-TW-WF CP indicated that PLDMV sparsely existed in different areas of Taiwan. Since all our PRSV-resistant transgenic papaya lines were susceptible to P-TW-WF, the virus was considered as an emerging threat for the application of the transgenic papaya in Taiwan and other regions.

\section{MATERIALS AND METHODS}

Virus isolation. The PRSV CP transgenic papaya lines (4) were evaluated in isolated test-fields at Taiwan Agricultural Research Institute, Wufeng, Taiwan, under the permit from the Council of Agriculture (3). During the fourth trial in 2000 to 2001, certain transgenic lines with high levels of resistance against PRSV started showing disease symptoms strikingly similar to that of severe PRSV infection. The possible virus in the samples collected from the infected lines was passaged by mechanical inoculation successively on plants of PRSV CP transgenic line 18-2-4, which was immune to PRSV infection (4). The virus extracted (in $10 \mathrm{mM}$ phosphate buffer, $\mathrm{pH}$ 7.0) from the infected transgenic line was subjected to serial dilution and inoculated on the plants of nontransgenic papaya cv. Tainung No. 2. The virus sample at the dilution endpoint was reprocessed by limiting dilution two more times to obtain a presumed pure culture. The isolate, designated tentatively as P-TW-WF isolate, was maintained in the plants of papaya cv. Tainung No. 2.

Host range test. Plants of 19 species (Table 1) belonging to seven families were mechanically inoculated with crude extracts from papaya plants infected with P-TW-WF isolate and maintained in a temperature-controlled $\left(\approx 25^{\circ} \mathrm{C}\right)$ greenhouse for observation of symptom development for 6 weeks. The infected plants that did not display symptoms were checked for the presence of the virus by mechanical inoculation of the plant extracts on healthy papaya plants (cv. Tainung No. 2), and the inoculated individuals were observed for symptom development under greenhouse conditions for 6 weeks.

Preliminary characterization of P-TW-WF isolate. For electron microscopy of the particles of P-TW-WF isolate, Formvarcoated grids were floated on the infected papaya leaf extract (in $10 \mathrm{mM}$ phosphate buffer, $\mathrm{pH}$ 7.0) for $2 \mathrm{~min}$, washed with distilled water and stained with $2 \%$ uranyl acetate $(\mathrm{pH} 4.2)(6)$. The infected leaves were fixed in $2 \%$ glutaraldehyde in $0.1 \mathrm{M}$ phosphate buffer ( $\mathrm{pH} 7.2$ ) at $4{ }^{\circ} \mathrm{C}$ for $4 \mathrm{~h}$, and then in $1 \%$ osmium tetroxide in the same buffer for $2 \mathrm{~h}$. The fixed tissues were dehydrated through increasing concentrations of ethanol, subjected to LR White resin-infiltration and finally embedded in LR White (19). The embedded specimens were sectioned with a diamond knife and the sections were double stained with $2 \%$ uranyl acetate and $0.4 \%$ lead citrate (34). Ultrastructural examination was carried out with a JEM-200 CX electron microscope (JEOL, Ltd., Tokyo, Japan).

To check the relationship of the isolate to PRSV, P-TW-WFinfected papaya plants were subjected to indirect enzyme-linked immunosorbent assay (ELISA) (39) with the antiserum to PRSV CP (41).

Reverse transcription-polymerase chain reaction (RT-PCR) and cloning of the $3^{\prime}$ terminal region of $P-T W-W F$ isolate. Total RNA was isolated from P-TW-WF-infected papaya leaves, using ULTRASPEC RNA isolation system (Biotex laboratories, Houston, TX). From $2 \mu \mathrm{g}$ of RNA, the first-strand cDNA was reverse transcribed with oligo- $\mathrm{dT}_{18}$ primer, using M-MLV reverse transcriptase (Promega, Madison, WI) following manufacturer's instructions. The degenerate primers Pot 1 and Pot2 $(10 \mathrm{pmol}$ each) for potyviruses, covering the C-terminal region of NIb and the N-terminal region of $\mathrm{CP}$ (7), respectively, were employed in the subsequent polymerase chain reaction (PCR) of the firststrand cDNA $(2 \mu \mathrm{l})$ with $2 \mathrm{U}$ of EX Taq DNA polymerase (TaKaRa, Shiga 520-21, Japan). Thirty-cycle amplification was performed adopting the thermal profile: denaturation for $1 \mathrm{~min}$ at $95^{\circ} \mathrm{C}$, annealing for $2 \mathrm{~min}$ at $55^{\circ} \mathrm{C}$ and synthesis for $3 \mathrm{~min}$ at $72^{\circ} \mathrm{C}$. The amplified product $(1.3 \mathrm{~kb})$ was cloned in the pCRII-

TABLE 1. Comparison of host reactions to Papaya leaf distortion mosaic virus (PLDMV) P-TW-WF from Taiwan and PLDMV isolates from Okinawa

\begin{tabular}{|c|c|c|c|c|c|}
\hline \multirow[b]{2}{*}{ Host } & \multicolumn{5}{|c|}{ Reactions to PLDMV isolate } \\
\hline & P-TW-WF & $\mathrm{J} 56 \mathrm{P}^{\mathrm{ab}}$ & $\mathrm{M}^{\mathrm{ab}}$ & $\mathrm{YM}^{\mathrm{ab}}$ & $\mathrm{T}^{\mathrm{ac}}$ \\
\hline Carica papaya (Tainung No.2) & DM & $\mathrm{DM}$ & MM & DM & - \\
\hline Cucumis metuliferus (Acc. 2459) & - & M & M & M & DM \\
\hline Cucumis sativus (Fountain) & - & nd & nd & nd & nd \\
\hline Cucumis sativus (Sagami-hansiro) & nd & M & M & MM & M \\
\hline Cuсurbita pepo (Diner) & - & M & CS & M & M \\
\hline Luffa acutangula & - & - & - & - & - \\
\hline Nicotiana benthamiana & - & - & - & - & M \\
\hline Nicotiana glutinosa & - & - & - & - & - \\
\hline Nicotiana rustica & - & nd & nd & nd & nd \\
\hline Phaseolus vulgaris & - & - & - & - & - \\
\hline Raphanus sativus & - & - & - & - & - \\
\hline Lycopersicum esculentum (Season Red) & - & nd & nd & nd & nd \\
\hline
\end{tabular}

${ }^{a}$ Results from Maoka et al. (25) and Maoka and Hataya, (23). CS, chlorotic spot; DM, distortion and mosaic; M, mosaic; MM, mild mosaic; nd, not determined; - , no infection; +, latent infection.

${ }^{\mathrm{b}} \mathrm{P}$ type isolates.

${ }^{\mathrm{c}} \mathrm{C}$ type isolates. 
TOPO vector (Invitrogen, Carlsbad, CA), and the insert sequenced (ABI377; Perkin-Elmer Applied Biosystems, Foster City, $\mathrm{CA}$ ). Based on the determined sequence, the primer PLDMVNCP (5'-CCCATGGAGTCCGCTCTTGATGCTGG-3', NcoI site underlined), aligning immediately downstream of the start codon of the CP coding frame (deduced from the known nucleotide sequence), was designed. To amplify the $3^{\prime}$ portion of the P-TWWF genome covering the whole $\mathrm{CP}$ gene and $3^{\prime}$ noncoding region, RT-PCR of the total RNA of infected leaf was performed with the forward primer PLDMV-NCP and the reverse primer 5'$\mathrm{dT}_{18}$ GAGCTCT-3' (SacI restriction site, underlined). The amplified 1.1-kb fragment was cloned in pCRII-TOPO vector to generate pPLDMVCP and the insert was sequenced as described previously. The sequences of the 1.3- and 1.1-kb fragments were assembled and the complete $\mathrm{CP}$ coding region and the entire $3^{\prime}$ untranslated region (UTR) were analyzed by the software VectorNTI-10.3.0 (Invitrogen, Fredrick, MD).

Construction of P-TW-WF CP-expression vector. From the first-strand cDNA synthesized as described previously, the genomic part of P-TW-WF reflecting the full $\mathrm{CP}$ reading frame was amplified by PCR using Ex-Taq DNA polymerase (Protech, Taiwan), with the forward primer PLDMV-NCP (5'-CCATGGAGTCCGCTCTTGATGCTGG-3', NcoI site underlined) and the reverse primer MDLCP879NotI (5'-CTCATACATTCACTGGCGCTCGATATTATTGCCGGCCGCAT-3', the NotI site underlined). Amplification was performed adopting the thermal profile: 30 cycles of denaturation at $94^{\circ} \mathrm{C}$ for $1 \mathrm{~min}$, annealing at $55^{\circ} \mathrm{C}$ for $2 \mathrm{~min}$ and synthesis at $72^{\circ} \mathrm{C}$ for $3 \mathrm{~min}$. The amplified DNA was cloned in pCRII-TOPO vector as described previously. The complete P-TW-WF CP reading frame was released from the pCRIITOPO vector backbone by NcoI-NotI restriction, and the released fragment was cloned in pET-32a(+) vector (Novagen, Madison, WI) restricted with the same enzymes to generate pET32a(+)WFCP. E. coli BL21(DE3) was transformed with pET$32 \mathrm{a}(+) \mathrm{WFCP}$ and the transformants were checked for the expression of the $51.8 \mathrm{kDa}$ thioredoxin- 6 histidine tag- $\mathrm{CP}$ fusion protein (described hereafter as P-TW-WF CP fusion protein), following standard procedures (32).

Purification of bacteria-expressed P-TW-WF CP fusion protein. Fractionation of the isopropyl- $\beta$-D-thiogalactoside (IPTG)-induced E. coli BL21(DE3) cells harboring the plasmid pET-32a(+)WFCP, and electrophoretic analyses of the fractions revealed the presence of the expressed P-TW-WF CP fusion protein in the insoluble inclusion bodies of the host. Thus, bacteria-expressed P-TW-WF CP fusion protein was purified from the insoluble fraction accordingly.

The E. coli cells centrifugally $(8,000 \times g, 10 \mathrm{~min})$ collected from 1 liter of IPTG-induced culture were suspended in (His-tag column) binding-buffer (20 mM Tris- $\mathrm{HCl}$ [pH 7.9], 0.5 M sodium chloride, $60 \mathrm{mM}$ imidazole) and lysed by French Press (Thermo Fisher Scientific Inc., Waltham, MA) at 18,000 psi. From the lysate, the bacterial inclusion bodies were collected by centrifugation at $5,000 \times g$ and suspended in $20 \mathrm{ml}$ of binding-buffer. This suspension was recentrifuged and the pellet was suspended in binding buffer with $6 \mathrm{M}$ urea, until complete dissolution. After the removal of the insoluble fraction by centrifugation (at $16,000 \times g, 30 \mathrm{~min}$ ), and subsequent filtration through $0.45 \mu \mathrm{m}$ filter, the inclusion body solution was loaded onto a His-tag column (Novagen, Madison, WI). After washing away the unbound fraction, the bound protein fraction was eluted with elution buffer (20 mM Tris- $\mathrm{HCl}$ [pH 7.9], $0.5 \mathrm{M}$ sodium chloride, and 1 $\mathrm{M}$ imidazole) with $6 \mathrm{M}$ urea. The P-TW-WF CP fusion protein was dialyzed against $20 \mathrm{mM}$ Tris- $\mathrm{HCl}(\mathrm{pH} 7.9), 0.5 \mathrm{M}$ sodium chloride, $60 \mathrm{mM}$ imidazole and $2 \mathrm{mM}$ 2-mercaptoethanol. All the described operations were performed at 0 to $4^{\circ} \mathrm{C}$.

Production of the antiserum against bacteria-expressed $P$ TW-WF CP. The antiserum against the bacteria-expressed P-TWWF CP fusion protein was produced in a New Zealand white rabbit. One milligram of purified $\mathrm{P}-\mathrm{TW}-\mathrm{WF} \mathrm{CP}$ fusion protein in $25 \mathrm{mM}$ Tris- $\mathrm{HCl}$ (pH 7.4), $192 \mathrm{mM}$ glycine, and $0.1 \%$ SDS was emulsified with an equal volume of Freund's complete adjuvant (Difco Laboratories Inc., Detroit, MI) and then injected intramuscularly into the hind legs of the rabbit. Subsequently, the same antigen, emulsified with Freund's incomplete adjuvant (Difco Laboratories Inc., Detroit, MI), was administered three times, at weekly intervals. Following the final injection, the rabbit was bled weekly, and the collected serum titers determined by SDS-immunodiffusion in $0.8 \%$ agarose substratum (29) with wells of $6 \mathrm{~mm}$ diameter separated by a distance of $4 \mathrm{~mm}$. The SDS-immunodiffusion plate was incubated at room temperature in a moisture chamber for $24 \mathrm{~h}$.

Serological analyses. To analyze the serological relationship of P-TW-WF with PRSV, the papaya plants infected with P-TW-WF or PRSV YK (5) were analyzed by indirect ELISA. Leaf extracts diluted appropriately in $50 \mathrm{mM}$ sodium carbonate buffer $(\mathrm{pH} 9.6)$ with $0.01 \%$ sodium azide were coated in the wells of a polystyrene microtitration plate. The antiserum to the bacteriaexpressed P-TW-WF CP fusion protein or the antiserum to PRSV CP (41), diluted 2,000-fold in conjugate buffer (PBST with $2 \%$ PVP-40 and $0.2 \%$ ovalbumin), was loaded into the plate $(200 \mu \mathrm{l}$ per well) and incubated at $37^{\circ} \mathrm{C}$ for $1 \mathrm{~h}$. After washing the wells three times with PBST, $200 \mu \mathrm{l}$ of alkaline phosphatase conjugated goat anti-rabbit immunoglobulin (KPL, Inc., Gaithersburg, MD), diluted 5,000-fold in conjugate buffer, was added to each well. After washing the wells three times with PBST, $100 \mu \mathrm{l}$ of $1 \mathrm{mg} / \mathrm{ml}$ $p$-nitrophenyl phosphate (Sigma-Aldrich Corporation, St. Louis, $\mathrm{MO})$ in substrate buffer (100 mM diethanolamine, $\mathrm{pH}$ 9.6) was added. The absorbance at $405 \mathrm{~nm}$ was measured on a Rainbow microplate reader (SLT Lab Instruments, Salzburg, Austria), 30 min after the addition of enzyme substrate.

Western blotting analysis was conducted using the antiserum to PRSV CP (41) or bacteria-expressed P-TW-WF CP fusion protein. Young leaves of P-TW-WF or PRSV YK-infected papaya plants were powdered in liquid nitrogen and the proteins were extracted in 6 volumes (wt/vol) of denaturation buffer $(50 \mathrm{mM}$ Tris- $\mathrm{HCl}$ [pH 6.8], 4\% sodium dodecyl sulfate [SDS], 2\% 2mercaptoethanol, $10 \%$ glycerol, $0.001 \%$ bromophenol blue). The extracts were heated at $95^{\circ} \mathrm{C}$ for $5 \mathrm{~min}$ and cleared by centrifugation at $8,000 \times g$ for $3 \mathrm{~min}$. Total soluble proteins in each sample $(10 \mu \mathrm{l})$ were resolved by SDS-polyacrylamide gel $(10 \%)$ electrophoresis (20), and subsequently transferred onto nitrocellulose membrane (PerkinElmer Life Sciences, Boston, MA). The membranes were treated with 4,000-fold diluted PRSVspecific or P-TW-WF-specific antiserum, and subsequently with 7,000-fold diluted alkaline phosphatase-conjugated goat antirabbit immunoglobulin (Kpl Co., Gaithersburg, MD). For visualization of immunosignals, the membrane was treated with $p$-nitroblue tetrazolium chloride and 5-bromo-4-chloro-3-indoyl-phosphate para-toluidine, as recommended by the manufacturers (Sigma-Aldrich Corporation, St. Louis, MO).

Island-wide survey for P-TW-WF-related isolates, cloning of CP genes, and phylogenetic analysis. After sequence analysis of the CP gene, P-TW-WF was identified as an isolate of PLDMV. To assess the extent of PLDMV prevalence in Taiwan, an island-wide survey for PLDMV isolates was conducted, by screening papaya plants displaying possible PLDMV symptoms by ELISA using the antiserum against bacteria-expressed P-TWWF CP fusion protein. By screening with the PRSV-resistant transgenic line 18-2-4 and successive serial passages on nontransgenic papaya plants as described, three new PLDMV isolates were obtained. To further characterize the isolates, total RNA isolated from the identified PLDMV-infected plants were subjected to RT-PCR with the primers 5'-ATGAAGGTGTTTCTCACCAG-3' (sequence-specific to $3^{\prime}$ end of NIb gene preceding $\mathrm{CP}$ gene) and oligo- $\mathrm{dT}_{18}$. The amplified products were cloned and sequenced, as described previously. 
The nucleotide sequences of the $\mathrm{CP}$ genes of P-TW-WF and the other three Taiwanese PLDMV isolates, P-TW-WZ, P-TW-ZS, and P-TW-TD (GenBank Accession Numbers EU240888, EU240889, and EU240890, respectively) were analyzed with those of three P type (J56P, J69P, and J179P; GenBank Accession Numbers AB088221, AB092814, and AB092815, respectively) and one C type (J199C; GenBank Accession Number AB092816) Japanese isolates of PLDMV (23). The alignment of PLDMV CP nucleotide sequences was performed by CLASTAL W program of the software VectorNTI-10.3.0 (Invitrogen, Fredrick, MD) and the phylogenetic analysis was conducted using PHYLIP 3.66 (12). Bootstrapping was produced 1,000 times by seqboot.exe program. Distance matrix was produced by prodist.exe program. The phylogenetic branch was set by neighbor.exe program and the consensus tree was produced by consense.exe program.

\section{RESULTS}

Symptomatology on transgenic and nontransgenic papaya. The isolate P-TW-WF caused vein-clearing and then mosaic on leaves of infected papaya seedlings 10 to 14 days after inoculation, strikingly similar to that caused by PRSV YK, a typical mosaic strain of PRSV from Taiwan (36). Moreover, like PRSV YK, the P-TW-WF isolate also induced water-soaking streaks on the petioles and stems of the infected papaya plants. However, 4 weeks after inoculation, the isolate P-TW-WF caused leaf narrowing and shoestringing, and apex stunting in the infected plants, unlike PRSV YK that caused leaf mosaic and minor distortion (Fig. 1). The P-TW-WF isolate also caused similar symptoms on the individuals of PRSV CP transgenic lines highly resistant (16-0-1, 17-0-5, and 18-2-4) or immune (18-0-9) to PRSV YK (Fig. 2) (4).

Host reactions. The $\mathrm{P}-\mathrm{TW}-\mathrm{WF}$ isolate did not infect the plants of any of the 19 species, except papaya (Table 1). To examine the possibility of latent presence of the virus, crude extracts of the symptomless plants were mechanically introduced into healthy papaya seedlings. The test plants observed for symptom develop- ment for more than 6 weeks did not show any evidence of viral disease symptoms.

Electron microscopy. Flexuous rod-like particles of about $800 \mathrm{~nm}$ were observed in the negatively stained crude sap extracted from the P-TW-WF-infected papaya leaf (Fig. 3A). The cytoplasmic inclusions observed in the ultrathin sections of the PTW-WF-infected papaya cells included typical potyviral pinwheels, scrolls, and long laminated aggregates (Fig. 3B).

Cloning and sequencing of the $3^{\prime}$ terminal region of $\mathrm{P}$-TWWF isolate. RT-PCR of the RNA from leaves of the plants infected with P-TW-WF, using degenerate primers Pot1 and Pot2 (7), yielded a 1.3-kbp DNA fragment. It was cloned in the pCRIITOPO vector and sequenced. Based on the determined sequence of the 1,272-bp DNA fragment, sequence-specific primers were designed and a 1,092-bp DNA fragment representing the extreme $3^{\prime}$ end of the P-TW-WF genome was amplified by RT-PCR. Overlapping assembly of the sequences of the 1,272- and 1,092-bp fragments yielded a sequence of 1,918 nucleotides that reflected the $3^{\prime}$ genomic region of the P-TW-WF isolate. Analysis of the protein coding potential of the sequence by VectorNTI-10.3.0 revealed a continuous stretch of 569 amino acids terminating at an amber codon located at nucleotides 1787 to 1789 . This protein coding region was followed by a noncoding region of 208 nucleotides demarcated by a $3^{\prime}$ polyA tail. The characterized $3^{\prime}$ portion of the P-TW-WF genome was deposited in the NCBI GenBank (Accession Number EF675245).

Sequence analysis of $3^{\prime}$ region of $P$-TW-WF isolate. The nucleotide BLAST analysis of the $3^{\prime}$ genomic region of the isolate P-TW-WF revealed its global alignment with the genomic RNA of PLDMV isolate J56P (23,24; NCBI GenBank Accession Number AB088221). This alignment (95\% identity) reached the terminus of the $3^{\prime}$ noncoding sequence (demarcated by the start of polyA tail), identifying the $1918 \mathrm{nt}$ sequence as the $3^{\prime}$ portion of PLDMV genome. The Protein-Protein BLAST analysis of the 569 amino acid-stretch deduced from the nucleotide sequence of PTW-WF revealed its alignment (95\% identity) with the polyprotein of PLDMV isolate J56P (24; NCBI GenBank Accession
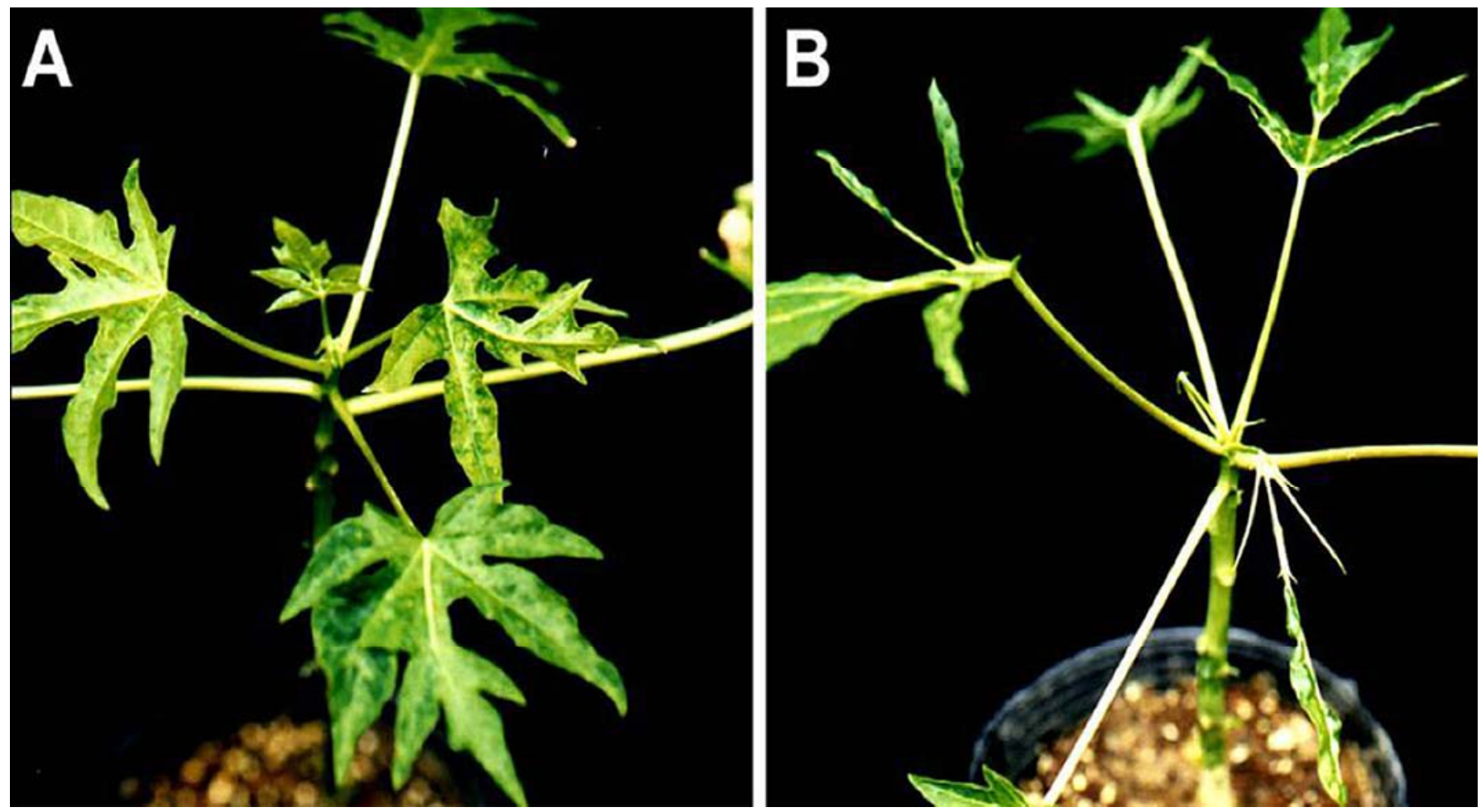

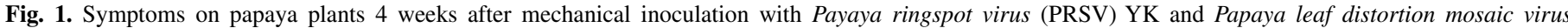

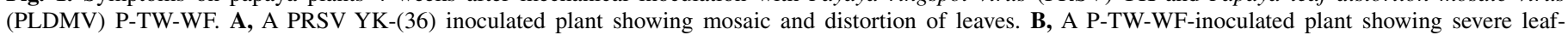
narrowing, distortion, and apex stunting. 
Number BAC80146), in the region representing NIb and CP of PLDMV. In 2-sequence blast, the deduced 293 amino acids of the $\mathrm{CP}$ (of molecular mass $33 \mathrm{kDa}$ ) of P-TW-WF aligned with the 293 amino acid CP sequence of J56P, with 94\% residue identity. Scrutiny of the junction of the $\mathrm{C}$ terminus of $\mathrm{NIb}$ and the $\mathrm{N}$ terminus of the CP of P-TW-WF revealed the presence of the putative processing site VSHQ/S (24). Moreover, the $3^{\prime}$ noncoding regions of P-TW-WF isolate (208 nucleotides) and J56P (209 nucleotides) showed $96.2 \%$ nucleotide identity. The alignment of the deduced amino acid sequence of the P-TW-WF CP with those of the CPs of four PRSV isolates (PRSV-P YK [36], PRSV-P HA [43], PRSV-W CI [24], and PRSV-W FL [31]) revealed 57.0 to $58.3 \%$ identities (Table 2), while the amino acid identities among the PRSV CPs were as high as 94.4 to $97.9 \%$. Altogether, the results of sequence analyses distinguished the PTW-WF isolate from PRSV isolates and identified the virus as an isolate of PLDMV.

Purification of bacteria-expressed P-TW-WF CP and antiserum preparation. The genomic part of $\mathrm{P}-\mathrm{TW}-\mathrm{WF}$ reflecting the full $\mathrm{CP}$ reading frame was cloned in $\mathrm{pET}-32 \mathrm{a}(+)$ to generate pET-32a(+)P-TW-WF-CP, with which E. coli BL21(DE3) was transformed. The bacteria-expressed P-TW-WF CP fusion protein was purified from the insoluble inclusion bodies of the host. The yield of the purified protein was estimated to be approximately
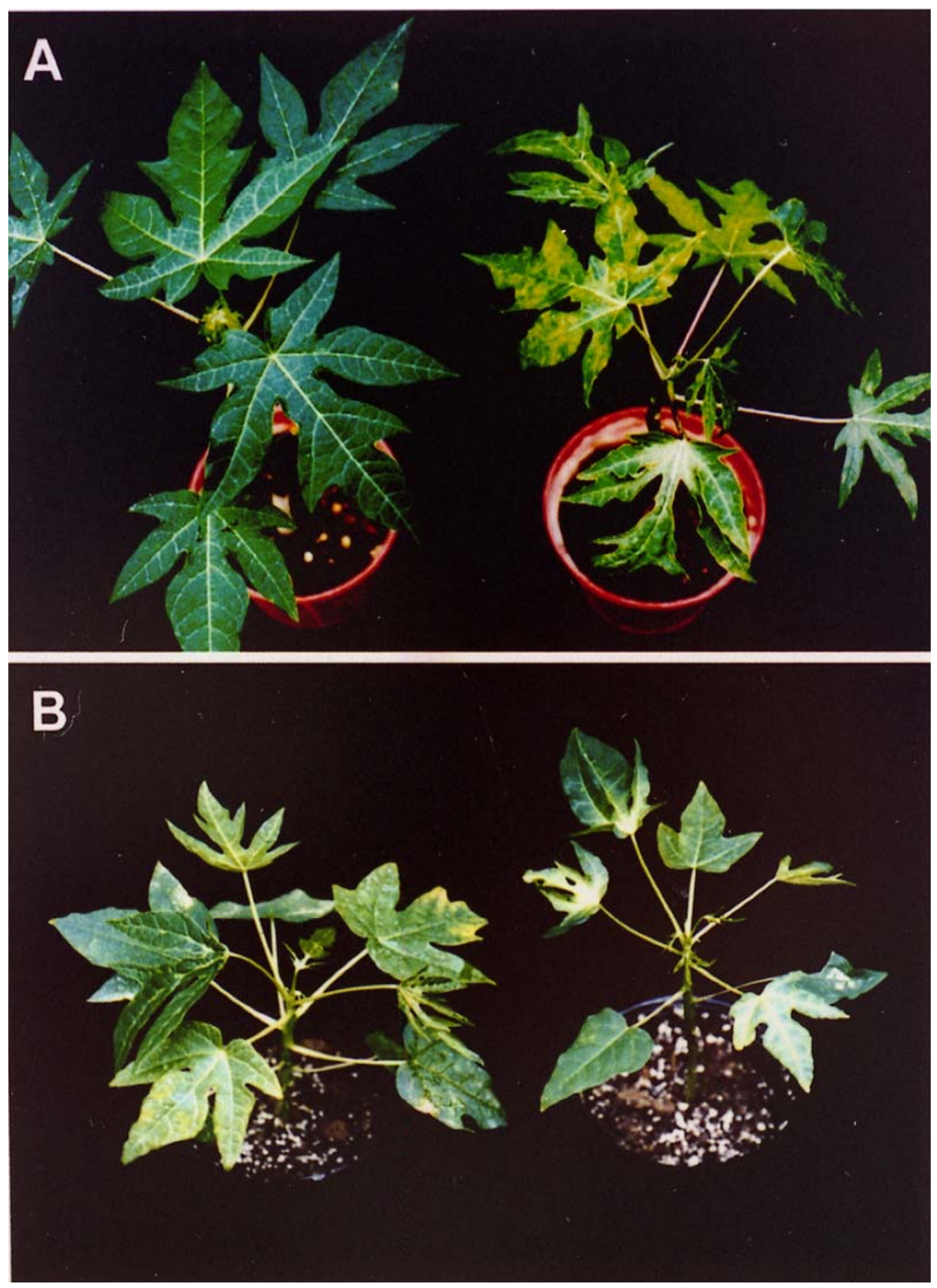

Fig. 2. Plants of Payaya ringspot virus (PRSV) coat protein-transgenic papaya line 18-0-9 inoculated with PRSV YK and Papaya leaf distortion mosaic virus PTW-WF. A, A transgenic plant showing no symptoms (left) and a nontransgenic plant displaying mosaic on leaves (right) 4 weeks after mechanical inoculation with PRSV YK (36). B, A transgenic plant (left) and a nontransgenic plant (right), both showing symptoms of leaf distortion and shoestringing 4 weeks after mechanical inoculation with P-TW-WF. 
$40 \mu \mathrm{g} / \mathrm{ml}$. The antiserum against P-TW-WF CP fusion protein was produced in a New Zealand white rabbit and the reactivity of the polyclonal antibody against the antigen was assessed by SDSimmunodiffusion. The dilution end point of the antiserum reacting with the antigen was $1 / 4$.

Lack of serological relationship between P-TW-WF isolate and PRSV. The results of serological analyses of crude antigens from PLDMV P-TW-WF-infected papaya plants against the antiserum to bacteria-expressed P-TW-WF CP or PRSV CP are shown in Figure 4. In ELISA, the extracts from the P-TW-WFinfected papaya plants reacted strongly with the antiserum to bacteria-expressed P-TW-WF CP. However, a reciprocal ELISA of the extracts of P-TW-WF-infected host individuals against the antiserum to PRSV CP did not show a significant immunoreaction (Fig. 4A). Likewise, the extracts from the PRSV YK-infected papaya plants did not react with the antiserum to bacteriaexpressed P-TW-WF CP, while the same reacted strongly with the antiserum to PRSV CP (Fig. 4A).

Western blotting analyses was performed to analyze the serological relationship of P-TW-WF CP and PRSV YK CP from
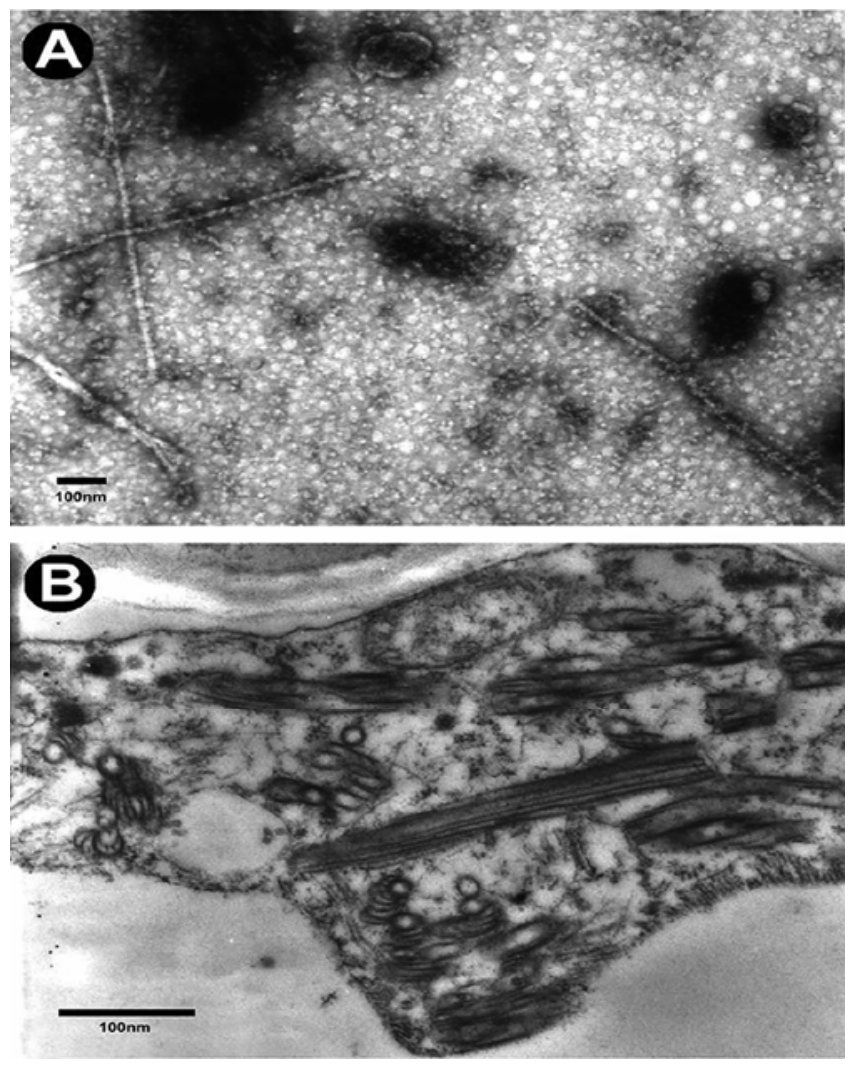

Fig. 3. Electron micrographs for virus particles and cytoplasmic inclusion bodies induced by P-TW-WF. A, Viral particles in the leaf extract from a PTW-WF-infected papaya plant. B, Thin section of P-TW-WF-infected papaya leaf showing cytoplasmic inclusions described as pinwheels, scrolls, and long laminated aggregates. the infected plants. Both P-TW-WF CP and PRSV CP antisera reacted strongly with homologous antigens, without any cross reaction with the heterologous antigens (Fig. 4B). The immunosignals smaller than the intact P-TW-WF CP (33 kDa) and PRSV $\mathrm{CP}(35 \mathrm{kDa})$ were considered to be the degraded fragments of CPs during protein extraction. Together, the results of ELISA and western blotting analysis revealed the lack of discernible serological relationship between the isolate P-TW-WF and PRSV.

Survey for PLDMV isolates in Taiwan and phylogenetic analysis. The papaya plants displaying possible PLDMV symp-

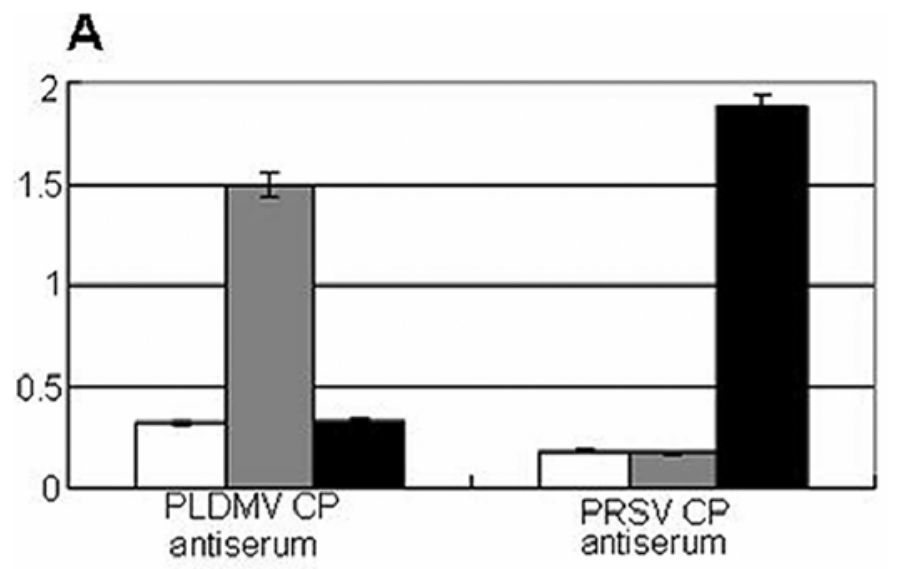

Healthy

PLDMV P-TW-WF infected

PRSV P-YK infected

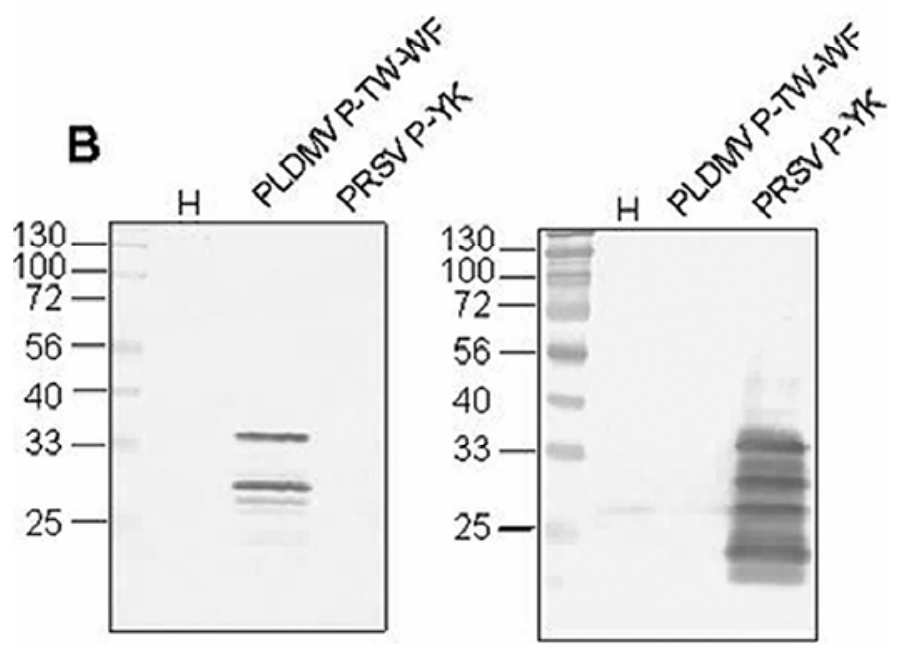

Fig. 4. Serological relationship of Papaya leaf distortion mosaic virus (PLDMV) P-TW-WF and Payaya ringspot virus (PRSV) YK analyzed by A, indirect enzyme-linked immunosorbent assay (ELISA) and $\mathbf{B}$, western blotting, using the antiserum to P-TW-WF CP or PRSV YK CP (41). For the analyses, infected-leaf samples of papaya plants were collected 4 weeks after inoculation with each virus.

TABLE 2. Comparison of amino acid sequence of the Papaya leaf distortion mosaic virus (PLDMV) P-TW-WF coat protein (CP) with those of various strains of PLDMV and Papaya ringspot virus (PRSV) ${ }^{\mathrm{a}}$

\begin{tabular}{lcccrr}
\hline Virus isolate & PLDMV (J56P) & PRSV-P (YK) & PRSV-P (HA) & PRSV-W (CI) & PRSV-W (FL) \\
\hline PLDMV (P-TW-WF) & 94.9 & 58.2 & 57.0 & 57.8 & 57.4 \\
PLDMV (J56P) & & 58.5 & 57.7 & 96.9 & 58.0 \\
PRSV-P (YK) & & & 95.1 & 95.1 & 97.9 \\
PRSV-P (HA) & & & & &
\end{tabular}

a Virus sources: PLDMV J56P (Okinawa strain; 24); PRSV-PYK (Taiwan strain; 36) and PRSV-P HA (Hawaii strain; 36); PRSV-W CI (Taiwan strain; 35); PRSV-

W FL (Florida strain; 31). The amino acid identities were accounted by the software VectorNTI-10.3.0. 
toms, collected from different areas of Taiwan, were screened by indirect ELISA using the antiserum against the bacteria-expressed P-TW-WF CP or PRSV YK CP (41). In this survey, out of 347 collected samples, 13 samples scattered in central, southern, and eastern Taiwan were found to be infected with PLDMV $(3.7 \%$ individuals), while one plant with PRSV and PLDMV together (0.28\% individuals), and the rest of the plants with PRSV (96\% individuals). The three isolates of PLDMV, namely P-TW-WZ, PTW-ZS, and P-TW-TD, collected from central (the first two) and eastern (the last one) parts of Taiwan, were established by successive serial passages through PRSV-resistant transgenic papaya lines and subsequent limiting dilutions. The clones representing the $\mathrm{CP}$ genes and the $3^{\prime}$ untranslated regions of the PLDMV isolates were sequenced for phylogenetic analysis with the $\mathrm{CP}$ genes of the Taiwanese PLDMV isolates and the Japanese isolates. In the generated phylogenetic tree (Fig. 5), the four PLDMV isolates collected from Taiwan are clustered as a single genetic group, segregating from the four Japanese isolates.

\section{DISCUSSION}

During the field evaluation of our PRSV YK CP transgenic papaya lines, certain transgenic lines, which had proved resistant or immune to PRSV consistently for several years, started showing severe disease symptoms. The disease symptoms, which resembled PRSV symptoms, were induced by a novel isolate eluding serological detection by an effective antiserum against PRSV CP, yet displaying potyvirus morphology. Subsequent sequence analyses of the RT-PCR-derived 3' region of the genome of the isolate, representing the coding regions of the $\mathrm{C}$-terminal region of $\mathrm{NIb}$, the complete $\mathrm{CP}$ and the $3^{\prime}$ noncoding sequence, established the identity of the deviant as an isolate of PLDMV. The present isolate of PLDMV, designated P-TW-WF, induced symptoms on papaya similar to those induced by PLDMV J56P reported from Okinawa, Japan (25).

Despite considerable genetic distance and lack of discernible serological relationship (24), PRSV and PLDMV are prone to be misidentified one for the other, based on disease symptom phenotype and viral morphology $(17,44)$. The island-wide survey for PLDMV by ELISA of symptomatic plants, using the antiserum against the bacteria-expressed P-TW-WF CP fusion protein, revealed PLDMV infection in a few plants $(<4.0 \%)$ and PRSV predominance $(>96 \%)$ in the papaya orchards. Moreover, the collection of PLDMV isolates from the regions of central and eastern parts of Taiwan suggested scattered distribution of the virus on the island. Since our transgenic papaya resistant to PRSV are susceptible to PLDMV, the virus may become an emerging threat after PRSV CP transgenic papaya is deregulated for cultivation in Taiwan. Thus, a future possibility of PLDMV gaining predominance over PRSV or causing a more dreaded synergism with PRSV to devastate papaya cultivation in Taiwan is a serious concern.

The potyviruses PRSV and PLDMV are well adapted and divergent to infect several cucurbits, with biotypes evolved to infect papaya $(1,2)$ designated respectively as PRSV $P$ (30) and PLDMV P (23) (the ancestral cucurbit infecting biotypes are named as PRSV W [30] and PLDMV C [23]). The genetic basis of the PRSV host-selectivity is not discernible by sequence comparisons $(1,2,16)$ or phylogenetic analyses $(21,28)$. This may be true also for PLDMV (23). Though the papaya infecting biotypes of PRSV are well adapted to infect papaya (30), they generally retain their ability to infect their cucurbit hosts, though it may be not a universal phenomenon. Unlike PLDMV J56P, which also infected several species of cucurbits (25), P-TW-WF and the other Taiwanese isolates collected in the present study, failed to infect all the tested non-papaya indicator hosts (Table 1), including the local lesion hosts, Chenopodium quinoa and C. amaranticolor, and the cucurbit hosts, Cucumis metuliferus, C. sativus, C. melo, and Cucurbita pepo. PRSV P can be transmitted experimentally to cucurbits, though its natural infection of cucurbits is a rare phenomenon (16). Similarly, PLDMV-P can infect cucurbits experimentally (23). In their inability to induce local lesion on Chenopodium species, the present P-TW-WF isolate and the $\mathrm{P}$ type PLDMV J56P isolate of Okinawa are similar. However, the P-TW-WF isolate's inability to establish infection on the tested cucurbit species characterizes itself as a new pathotype of PLDMV.

PRSV and PLDMV enjoy a mutual geographical predominance over each other: PRSV is prevalent and a major limiting factor for papaya cultivation in Taiwan, Hawaii, Mexico, Brazil, and most other papaya growing countries $(30,40)$, while this distinction is secured by PLDMV in Japan (17,25). Co-existence of PRSV and PLDMV in a single host individual has not been reported. However, in the present survey, at least one individual supporting the coexistence of PRSV and PLDMV was encountered.

Various phylogenetic analyses of the isolates of PRSV $(1,2,11$, 27,28) or PLDMV (23) revealed close genetic relationship among the isolates collected within a geographical region and their divergence, as a group, from those of other geographical regions. These studies support possible indigenous origin of papayainfecting pathotypes from local cucurbit-infecting pathotypes by mutation, through transfer of strains (2) between geographical

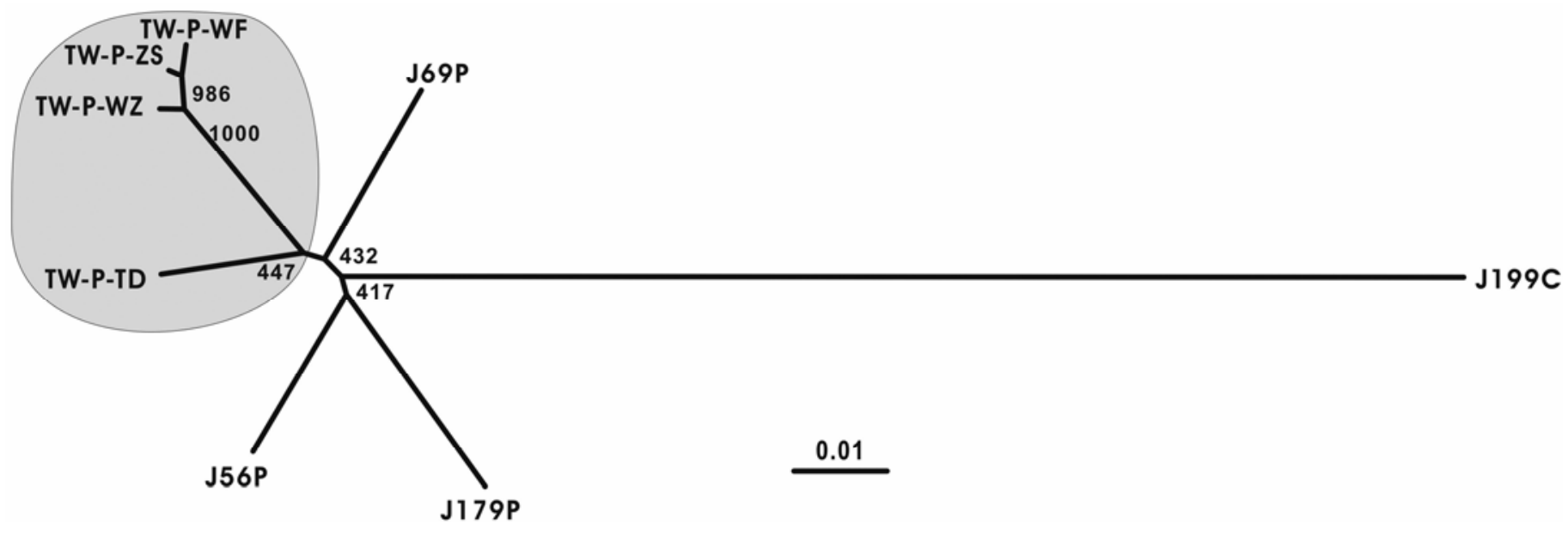

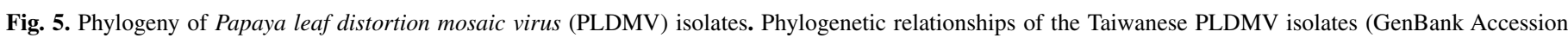

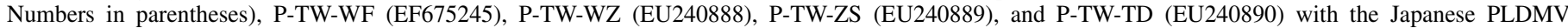

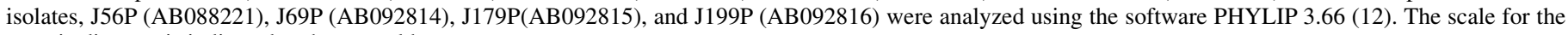
genetic distance is indicated at the central bottom. 
zones, and recombination $(2,28)$ between distantly related strains could also cause divergence. The present sequence analyses and phylogenetic analysis of the PLDMV isolates of Taiwan revealed their close genetic relationship and their divergence, as a group, from the isolates of Japan (Fig. 5). The indigenous origin-based close genetic relationships of PRSV or PLDMV isolates within geographical boundaries possibly preserve, in the viral genome, the sequence requirements that can function as host resistanceconferring elements in transgenic contexts. This notion is supported by the effectiveness of PRSV CP transgenic papaya lines against PRSV isolates from a geographical area to which the transgene donor belongs $(14,22,33)$.

Our papaya transgenic lines described earlier (4) and also several of our papaya lines produced later consistently proved highly resistant or immune to PRSV isolates from Taiwan and also from other geographical regions, however, all of them showed susceptibility to PLDMV. Hence, in this juncture, PLDMV CP transgenic papaya lines resistant to PLDMV have been generated by our laboratory. We hope PRSV-PLDMV double transgenic lines would be generated by crossing these lines with the existing PRSV-resistant transgenic lines. To ensure generation of effective transgenic papaya lines resistant to PRSV and PLDMV, transformation of appropriate nontransgenic papaya cultivars with chimeric constructs comprising (full or parts of) PRSV YK and PLDMV P-TW-WF CP genes is also currently undertaken. This option will prevent undesirable independent segregation of PRSV and PLDMV CP transgenes that can deprive descendants of their transgenic resistance to PRSV or PLDMV. Since the PLDMV isolates collected from various regions of Taiwan show very close genetic relationship among themselves, the future PRSV-PLDMV double transgenic papaya lines are expected to be effective against various PLDMV isolates of Taiwan.

\section{ACKNOWLEDGMENTS}

This study was supported in part by the research grants NSC 93-2313B-265-001 (National Science Council, Taiwan, R.O.C); 94AS-5.2.1-STa1, 95AS-6.1.3-FD-Z1, and 96AS-1.2.1-ST-a2 (Council of Agriculture, Taiwan, R.O.C).

\section{LITERATURE CITED}

1. Bateson, M. F., Henderson, J., Chaleeprom, W., Gibbs, A. J., and Dale, J. L. 1994. Papaya ringspot potyvirus: Isolate variability and the origin of PRSV type P in Australia. J. Gen. Virol. 75:3547-3553.

2. Bateson, M. F., Lines, R. E., Revill, P., Chaleeprom, W., Ha, C. V., Gibbs, A. J., and Dale, J. L. 2002. On the evolution and molecular epidemiology of the potyvirus Papaya ringspot virus. J. Gen. Virol. 83:2575-2585.

3. Bau, H. J., Cheng, Y. H., Yu, T. A., Yang, J. S., Liou, P. C., Hsiao, C. H., Lin, C. Y., and Yeh, S. D. 2004. Field evaluations of transgenic papaya lines carrying the coat protein gene of Papaya ringspot virus in Taiwan. Plant Dis. 88:594-599.

4. Bau, H. J., Cheng, Y. H., Yu, T. A., Yang, J. S., and Yeh, S. D. 2003. Broad-spectrum resistance to different geographic strains of Papaya ringspot virus in coat protein gene transgenic papaya. Phytopathology 93:112-120.

5. Cheng, Y. H., Yang, J. S., and Yeh, S. D. 1996. Efficient transformation of papaya by coat protein gene of Papaya ringspot virus mediated by Agrobacterium following liquid-phase wounding of embryogenic tissues with Carborundum. Plant Cell Rep. 16:127-132.

6. Christie, S. R., Purcifull, D. E., Crawford, W. E., and Ahmed, N. A. (eds.) 1987. Page 45 in: Electron microscope of negatively stained clarified viral concentrates obtained from small tissue samples with appendices on negative staining techniques. Fla. Agric. Exp. Stn. Bull. No. 872.

7. Colinet, D., Kummert, J., Lepoivre, P., and Semal, J. 1994. Identification of distinct potyviruses in mixedly-infected sweetpotato by the polymerase chain reaction with degenerate primers. Phytopathology 84:65-69.

8. Conover, R. A. 1976. A program for development of papaya tolerant to the distortion ringspot virus. Proc. Fla. State Hortic. Soc. 89:229-231.

9. Conover, R. A., and Litz, R. E. 1978. Progress in breeding papaya with tolerance to Papaya ringspot virus. Proc. Fla. State Hortic. Soc. 91:182-184.

10. Conover, R. A., Litz, R. E., and Malo, S. E. 1986. 'Cariflora'- a papaya ringspot virus tolerant papaya for South Florida and the Caribbean.
HortScience 21:1072.

11. Davis, M. J., and Ying, Z. 1999. Genetic diversity of the Papaya ringspot virus in Florida. Proc. Fla. State Hortic. Soc. 112:194-196.

12. Felsenstein, J. 1989. Phylip-Phylogeny inference package (version 3.2). Cladistics 5:164-166.

13. Fitch, M. M. M., and Manshardt, R. M. 1990. Somatic embryogenesis and plant regeneration from immature zygotic embryos of papaya (Carica papaya L.). Plant Cell Rep. 9:320-324.

14. Fitch, M. M. M., Manshardt, R. M., Gonsalves, D., Slightom, J. L., and Sanford, J. C. 1990. Stable transformation of papaya via microprojectile bombardment. Plant Cell Rep. 9:189-194.

15. Fitch, M. M. M., Manshardt, R. M., Gonsalves, D., Slightom, J. L., and Sanford, J. C. 1992. Virus resistant papaya derived from tissues bombarded with the coat protein gene of Papaya ringspot virus. Bio/Technology 10:1466-1472.

16. Gonsalves, D. 1998. Control of Papaya ringspot virus in papaya: A case study. Annu. Rev. Phytopathol. 36:415-437.

17. Kawano, S., and Yonaha, T. 1992. The occurrence of papaya leaf distortion mosaic virus in Okinawa. Technical Bulletin of Food and Fertilizer Technology Center, Taipei, Taiwan 132:13-23.

18. Kiritani, K., and Su, H. J. 1999. Papaya ringspot, banana bunchy top, and citrus greening in the Asia and Pacific region: Occurrence and control strategy. Jpn. Agric. Res. Q. 33:23-30.

19. Ko, N. J. 1987. LR White embedding for immunogold labelling of viralinfected plant tissues. Proc. Natl. Counc. Bull. R.O.C. 11:206-211.

20. Laemmli, U. K. 1970. Cleavage of structural proteins during the assembly of the head of bacteriophage T4. Nature 227:680-685.

21. Lima, R. C. A., Souza, M. T., Jr., Pio-Ribeiro, G., and Lima, J. A. A. 2002. Sequences of the coat protein gene from Brazilian isolates of Papaya ringspot virus. Fitopatol. Bras. 27:174-180.

22. Lines, R. E., Persley, D., Dale, J. L., Drew, R., and Bateson, M. F. 2002. Genetically engineered immunity to Papaya ringspot virus in Australian papaya cultivars. Mol. Breed. 10:119-129.

23. Maoka, T., and Hataya, T. 2005. The complete nucleotide sequence and biotype variability of papaya leaf distortion mosaic virus. Phytopathology 95:128-135.

24. Maoka, T., Kashiwazaki, S., Tsuda, S., Usugi, T., and Hibino, H. 1996. Nucleotide sequence of the capsid protein gene of papaya leaf distortion mosaic potyvirus. Arch. Virol. 141:197-204.

25. Maoka, T., Kawano, S., and Usugi, T. 1995. Occurrence of the P strain of Papaya ringspot virus in Japan. Ann. Phytopathol. Soc. Jpn. 61:91-94.

26. Mekako, H. U., and Nakasone, H. Y. 1975. Interspecific hybridization among six Carica species. J. Am. Soc. Hortic. Sci. 100:294-296.

27. Noa-Carrazana, J. C., González-de-León, D., Ruiz-Castro, B. S., Piñero, D., and Silva-Rosales, L. 2006. Distribution of Papaya ringspot virus and Papaya mosaic virus in papaya Plants (Carica papaya) in Mexico. Plant Dis. 90:1004-1011.

28. Noa-Carrazana, J. C.; González-de-León, D., and Silva-Rosales, L. 2007. Molecular characterization of a severe isolate of Papaya ringspot virus in Mexico and its relationship with other isolates. Virus Genes 35:109-117.

29. Purcifull, D. E., and Batchelor, D. L. 1977. Page 39 in: Immunodiffusion tests with sodium dodecyl sulfate (SDS)-treated plant viruses and plant viral inclusions. Fla. Agric. Exp. Stn. Bull. 788 (Tech).

30. Purcifull, D. E., Edwardson, J. R., Hiebert, E., and Gonsalves, D. 1984. Papaya ringspot virus. No. 292 in: Descriptions of Plant Viruses. Commonw. Mycol. Inst., Kew, England.

31. Quemada, H., Hostis, B. L., Gonsalves, D., Reardon, I. M., Heinrikson, R., Hiebert, E. L., Sieu, L. C., and Slightom, J. L. 1990. The nucleotide sequence of the $3^{\prime}$ terminal regions of Papaya ringspot virus strains W and P. J. Gen. Virol. 71:203-210.

32. Sambrook, J., and Russell, D. W. 2001. Molecular Cloning: A Laboratory Manual. 3rd ed. Cold Spring Harbor, NY.

33. Tennant, P. F., Gonsalves, C., Ling, K. S., Fitch, M., Manshardt, R., Slightom, J. L., and Gonsalves, D. 1994. Differential protection against Papaya ringspot virus isolates in coat protein gene transgenic papaya and classically cross-protected papaya. Phytopathology 84:1359-1366.

34. Venable, J. H., and Coggeshall, R. 1965. A simplified lead citrate stain for use in electron microscope. J. Cell Biol. 25:407-408.

35. Wang, C. H., and Yeh, S. D. 1992. Nucleotide sequence comparison of the $3^{\prime}$ terminal region of severe, mild and non-papaya infecting strains of Papaya ringspot virus. Arch. Virol. 127:345-354.

36. Wang, C. H., and Yeh, S. D. 1997. Divergence and conservation of the genomic RNAs of Taiwan and Hawaii strains of papaya ringspot potyvirus. Arch. Virol. 142:271-285.

37. Wang, H. L., Wang, C. C., Chiu, R. J., and Sun, M. H. 1978. Preliminary study on Papaya ringspot virus in Taiwan. Plant Prot. Bull. 20:133-140.

38. Yeh, S. D., and Gonsalves, D., 1984. Purification and immunological analysis of cylindrical-inclusion protein induced by Papaya ringspot virus and Watermelon mosaic virus 1. Phytopathology 74:1273-1278.

39. Yeh, S. D., and Gonsalves, D. 1985. Translation of papaya ringspot virus 
RNA in vitro: Detection of a possible polyprotein processed for capsid protein, cylindrical-inclusion protein and amorphous-inclusion protein. Virology 143:260-271.

40. Yeh, S. D., and Gonsalves, D. 1994. Practices and perspective of control of Papaya ringspot virus by cross-protection. Adv. Dis. Vector Res. 10:237-257.

41. Yeh, S. D., Gonsalves, D., and Provvidenti, R. 1984. Comparative studies on host range and serology of Papaya ringspot virus and Watermelon mosaic virus 1 . Phytopathology 74:1081-1085.
42. Yeh, S. D., Gonsalves, D., Wang, H. L., Namba, R., and Chiu, R. J. 1988. Control of Papaya ringspot virus by cross protection in Taiwan. Plant Dis. 72:375-380.

43. Yeh, S. D., Jan, F. J., Chiang, C. H., Doong, T. J., Chen, M. J., Chung, P. H., and Bau, H. J. 1992. Complete nucleotide sequence and genetic organization of Papaya ringspot virus RNA. J. Gen. Virol. 73:2531-2541.

44. Yonaha, T., Yonemori, S., and Tamori, M. 1976. Relation between the flight occurrence of alate aphids and the spread of papaya virus disease in the field. Okinawa Agric. 14:7-15. 